\title{
Introduction
}

\section{Area Studies and Study Abroad in the 21st Century}

\author{
The future now belongs to societies that organize themselves for learning.
}

\section{- Ray Marshall and Marc Tucker, Thinking for a Living, xiii}

Few today would argue with the conviction that nearly every phase of our daily lives is shaped and informed by global societies, corporations, events and ideas. More than ever before, it is possible to claim that we are increasingly aware of the dynamic power and penetrating effects of global flows on information, technology, the sciences, the arts, the humanities, and languages. Borderless, spaceless and timeless, such sources of knowledge, it appears, are effortlessly digested and disseminated without clocks, calendars, or physical limitations. It is, of course, a mistake to believe that packages of "instant" knowledge that appear to wing their way at megahertz speeds in and through our earthly lives account for all or nearly all that there is to know-or, more importantly, to learn-about our communities, regions and the globe itself.

On the contrary: the "knowing" about how to live, to work, to prosper, or to understand ourselves and those around us is not what educators mean when they speak of intellectual achievement and practical understanding. It is the "learning" about us, our societies and our global knowledge that lies at the heart of the international educator's life work, and it is the learning that is the most controversial aspect of education. The act of "learning," in fact, is less objective and more subjective, is less passive and more active, and is less superficial and more profound in each of our lives. By definition, a responsible learner is one who takes on the intellectual challenge and the social and personal obligation to leave this globe a better place for those who follow, who assumes the life work of influencing the lives of others, and who is committed to making the best of every opportunity both within the reach and beyond the vision of the mind's eye.

Study abroad has traditionally been viewed as a time of seeing and viewing, however passively, the differences and similarities of other peoples, societies and cultures. The period of knowing about what others do or say can occur at any time during one's life; however, the "knowing" of studying abroad is accomplished in the college years prior to the accumulated knowledge about practical learning and living. In this respect, study abroad has been seen as an experience which may or may not invest the students in greater or lesser insights about the peoples, societies or cultures around them. Further, when study abroad is bound up with travel or movement from place to place, it can become a passive act, so much so that travel rather than learning becomes the goal of the study abroad experience. Simply put, the more that one travels, the more, it is argued, one learns. Furthermore, while seen as desirable for "classroom learning," some would say that no amount of academic preparation appears to be useful in the 
enterprise of the travel experience, since so many experiences are unpredictable, individualized and, in some cases, arbitrary.

From the perspective of study abroad, it might be said that the gods of area studies no longer completely fulfill our students' needs, while the gods of global studies have not yet fulfilled their promises. Janus-like, international educators look in one direction at a still highly intense and valued picture of local cultures and identities, and in another direction toward an increasingly common culture, economy and society. The former appears to celebrate the differences and "uncommonness" of the human experience while the latter smoothes over the differences to underscore the commonalities and sameness of our contemporary world. The choice appears to be between the particular and the universal, the local and the global.

Academic preparations, such as area studies programs, appear to be unnecessary for the individualized forms of learning, such as study abroad. Indeed, since an area studies preparation may raise or strengthen stereotypical perceptions of the overseas peoples, societies and cultures, it has been argued that it best be left aside. In this context, students are viewed as a tabula rasa on which new discoveries from living and studying overseas leave an imprint or impression. It seems that sending as many students as possible in as many directions as possible has become the dominant study abroad objective. Thus, "whole world" presentations and documentation often rely on the "other" as the learning objective with little or no attempt to discriminate or distinguish the levels of learning that such "whole world" immersion entails. In recent times, additional concerns about liability, health, safety and comfort levels have been added to the "pre-departure" orientations and training programs. The "student as selflearner" continues to be viewed and treated as a "customer knowledge-consumer" within both U.S. private and public colleges and universities. In the age of "globalization," it is the conviction of the editors of Frontiers that knowledge consumption is only a small aspect of the 21st century international educators' arsenal. More importantly, it will be argued in this special issue on area studies and Study Abroad that the intellectual development of the U.S. undergraduate needs to be enhanced with skills of self-learning and transdisciplinary perspectives on local and regional cultures and languages.

The authors contributing to this special thematic issue of Frontiers have been asked to bring their state-of-the-art thinking on area studies to bear on the key question confronting study abroad: How does specialized understanding of geographical and cultural areas of the world enhance and strengthen undergraduate learning on and beyond our campuses? In other words, in what ways do area studies inform overseas learning through the activity of study abroad? The variety of responses demonstrates two principal ways in which area studies has begun to reformulate its goals and strategies. First, area studies reaffirms a commitment to local and regional comprehensive research and teaching, and redefines its mission in terms of the need to come to grips with local knowledge and specific social and cultural practices within a globalized world. Second, area studies specialists question long-held definitions of 
concepts, including those of "geographical area" and "globalization," in order to maximize contributions to

U.S. undergraduate learning.

David Ludden begins our issue with a review of the Social Science Research Council and the Ford Foundation's understanding of the transition in area studies from the Sputnik era to the globalization era. Ludden notes the faculty dilemma in working in an "area." He points out the political interests of the Cold War for public funding of such specialized academic skills, skills which, whether funded by the government or not, were and continue to be defined by the scholar first and then by finances. Drawing on his own experience at the South Asia Institute at the University of Pennsylvania, Ludden takes the reader through the intellectual rationale for area studies, and how that rationale is being redefined in favor of stronger area studies in the present globalization era. Gregory Kulacki's study of China and the Chinese experience points accurately to one approach to defining area studies; that is, in terms of the peoples and cultures studied. In a sense, Kulacki makes it clear that Chinese studies is "legitimate" and has authority as long as it reflects the Chinese themselves, their experiences and lives. Ann Curthoys, on the other hand, notes the growing importance of defining Australians and Australian studies not only in terms of the changing experiences of contemporary Australia, but also in terms of the demands of non-Australians, who ask for more precision in defining Australians, their history, society and cultures.

Richard Beach and George Sherman take on a more difficult matter, at least from the viewpoint of U.S. faculty and students. Canada is rarely seen as a study abroad site for U.S. students, not only because of its geographical position but also for its cultural and historical proximity. The overall U.S. view, albeit unflattering, is that Canada and Canadians are very much like the U.S. and Americans, so why study in Canada? Beach and Sherman argue that history, languages, and borders do make a difference, both physically as well as culturally. Using the argument of the previous area studies specialists, they are interested in the ways that Canadians have shaped and informed their cultural and social identities in the teeth of U.S. economic and political domination in the region. The implications of globalization are, perhaps, more immediately evident in the Canadian case than in any other world region. U.S. students would do well to observe the processes of adaptation and acculturation first-hand by studying and living in Canada. James Petras gives us a broader vista of regional adaptation to the economic and political forces of globalization with his essay on Latin America. Indeed, Latin America has a dynamic similar to that of Canada due to its physical, cultural and historical proximity to the U.S. It would be a mistake to see Latin America only in terms of the north-south regional dynamics, since Europe, Asia and Africa have also shaped both past and present structures and institutions within that region in ways far more dramatic than has the United States. Study abroad, Petras reminds us, is an excellent way of learning directly about Latin American societies, cultures and politics from Latin Americans themselves, a learning that may be widely different from the official U.S. 
diplomatic and corporate perspectives. Finally, the very familiar world regions, such as England, offer in some cases more challenges to the U.S. undergraduate than might be expected. Jane Edwards looks at Britain and all that U.S. students may or may not know about that culture and society. The study of Britain lends itself, Edwards argues, to more than the usual challenges, due to the preconceived notions that U.S. students bring with them to, say, London. Understanding the "European-ness" of Britain and its historic relationship with continental Western Europe will justify the need to see Britain as less familiar and more complex, thus necessitating the need to study, visit and live in parts of Britain and Western Europe. In this case, the area does define the country, its identity and culture in a historical interplay of social, cultural and economic forces.

David Lloyd, Philip Khoury and Russell Bova invite the reader to return to large regional perspectives through African, Middle Eastern and Russian area studies. David Lloyd presents an analysis of the broad and immediate contexts of African studies. While recognizing the difficulty of establishing consistently causal links between African studies and study abroad in Africa, he delineates the significance of local, experiencebased study for the development of collaborative African studies research. Lloyd argues that the benefits of study abroad in Africa to African studies belie the relatively small number of students involved. Further, assessment for funding and other purposes needs to utilize criteria that take into account the challenges of on-site study in Africa and the depth of post-study abroad participation not just in African studies per se, but in other related areas as well. Considering the recent past of Middle East studies, Philip Khoury charts its response to post-Cold War criticism. He illustrates new directions the field is taking towards including different geographic areas, and new emphasis in organizational priorities, noting the importance of funding for providing first-hand contact for students in Middle Eastern studies with scholars from the Middle East. Khoury assesses the impact of recent historical and political events in the area on Middle Eastern studies, and looks toward more inclusive research efforts.

Russell Bova examines another region that has undergone considerable political, social and economic change in the 2oth century. Having moved from empire to soviet socialist states and now to a confederation of nation states, Russia and, naturally, Russian area studies, offer an excellent example of local and regional complexities both in the nomenclature of the region and in the changes in Russian studies programs. Bova illustrates the need to understand the specific dynamics of local communities in their relationship to larger administrative units such as provinces, states and national capitals. In referring to the "double transition" of contemporary Russia, Bova reminds us that globalization is both a grass roots and elite process with many unlikely "bedfellows" that is also changing more rapidly each decade than had been the case fifty years ago.

Finally, Richard Falk and Nancy Kanach collaborate to discuss the ways in which globalization and study abroad are emerging in the post-Cold War period. The sudden shifts of economic and political power make our world more fragile and more difficult to comprehend without considering the "computer gap" that is rapidly leaving whole 
communities and even nations in a more uneven relationship with the power brokers than ever before. The need to reflect with care and precision through area studies is complemented by the additional pressing need to study, see and learn outside of the U.S. Globalization means promoting study abroad and reaffirming the strengths of local and regional studies.

Taken together, these essays invite international educators to reconsider notions of learning before, during and after study abroad. The writers view study abroad as an opportunity for social and intellectual engagement with other peoples and with oneself. The essays point to a variety of ways of intellectually preparing our students for their initial encounters with sets of real-life global experiences. Reflecting on such engagement and encounters allows students to begin to formulate, with increasing sophistication, specific and general concepts about individual differences, local and regional commonalities, and the global transformations of our present era. In light of the current area studies debates, we might also reconsider approaches to pre-departure preparations, create onsite projects, and reorganize the overseas curricula of study abroad programs themselves. In particular, students can continue to benefit from area and global studies programs back on the home campus upon their return, where they can enter effectively into scholarly debates and continue the learning and personal growth that began while they were abroad.

Frontiers welcomes comments and suggestions for future special issues. We see ourselves and our field of international education in greater need of close cooperation with our faculty colleagues both in terms of defining the work of international learning, and in terms of formulating and designing international or global programs. We thus invite our readers to see Frontiers as a forum for such academic exchanges, and promise that Frontiers will respond to articles, essays, book reviews and reviews of resources for study abroad with collegial interest and enthusiasm.

We wish to thank especially Brian Whalen, Rhoda Borcherding and our other colleagues on the Editorial Board for their support, encouragement and assistance in completing this special issue. We are particularly pleased with the authors and their willingness to listen to our requests and comments.

Thomas Ricks, Villanova University Katharine Krebs, SUNY Binghamton Michael Monahan, Macalester College

\section{Suggestions for Further Reading}

Altbach, Philip G. and Patti McGill Peterson, eds. Higher Education in the

21st Century: Global Challenge and National Response. IIE Research 
Report Number 29. Annapolis, MD: IIE Books, 1999.

This slim volume focuses on principal topics for colleges and universities to consider both locally and globally. Philip Altbach and Todd Davis set the tone of the volume with their "notes for an international dialogue on higher education." Stressing the need for practical education, the authors also raise issues about the role of technology, the increase in "internationally mobile students," the global role of graduate education, privatization of higher education, committed faculty and the threats of "managerialized" universities. The eight responses to the opening themes address specific issues for China, India, Africa and South Africa, Latin America, Japan and Europe. The work is a very good discussion text for international educators and their area studies faculty colleagues, and also provides a theoretical basis for the design and development of overseas programs.

Stephen R. Graubard, ed. "Education Yesterday, Education Tomorrow.” Daedalus. Vol. 127, No. 4 (Fall, 1998).

The eleven authors of this issue of the Journal of the American Academy of Arts and Sciences build off the Fall 1995 issue of Daedalus and its topic of "American Education: Still Separate, Still Unequal." While neither accepting nor rejecting the thrust of A Nation at Risk, the authors look both at what has occurred over the past three decades, and at what is on the horizon for the next decade. In stressing reforms of systems and innovative ways of learning, the authors' discussions invite the international educator to address a variety of ways in which students learn and to challenge the system in which they thrive.

\section{WWW. NAFSA.ORG/SECUSSA.WHYSTUDY}

In 1989, NAFSA and COUNCIL created the Whole World Committee (WWC). Initially chaired by John Sommers and now chaired by Mick Vandenberg, the WWC set out to find ways by which U.S. students could and would choose non-European overseas sites for a semester of study and learning. One of the tasks that the WWC accomplished was the creation of four area study essays on Africa, Asia, South America and the Middle East. Each essay, entitled "Why Study in ...," addresses basic fears and stereotyping of the non-European world regions. The essays then focus on benefits, health and safety, "getting started," housing, and practical learning in each of these regions. In newlyattached longer versions, the essays also have a bibliography and more informative texts. The shorter versions were published serially in Transitions Abroad. NAFSA has added two additional important essays to this website, on "Class and Study Abroad" and "An African-American in South Africa." Overall, the readers of Frontiers will be welladvised to access the articles at the website and consider using all the essays in their pre-departure orientation training, faculty area studies discussion groups, and in welcome-back sessions for returning students.

Richard Falk. Predatory Globalization: A Critique. Cambridge, UK: Polity 
Press, 1999.

The thesis of Richard Falk's critique is that “predatory globalization' has eroded, if not altogether broken, the former social contract that was forged between state and society during the last century or so" (p. 3). The breaking of that contract resulted from the state's "deference to the discipline of global capital" and the neglect of the common good. Falk argues that only the "massing of strong transnational social pressures on the states of the world could alter the political equation to the point where the state could sufficiently recover its autonomy in relation to the world economy." He demonstrates the emergence of a new kind of transnational politics referred to as "globalization-frombelow." In restoring "global civil society," this new politics will need to move forward with the project of cosmopolitan democracy, including the protection of human rights. For the international educator, creating overseas programs that allow for a better understanding of the interconnectedness of regional and global levels is an admirable goal. More important, however, are those programs that offer

U.S. undergraduates insights into "world order priorities" such as global poverty, protection of the planet, the sources of transnational violence, and "responsible sovereignty" in ways rarely found in traditional classroom learning on our campuses.

Mark Tessler, Jodi Nachtwey and Anne Banda. Eds. Area Studies and Social

Science: Strategies for Understanding Middle East Politics. Bloomington

and Indianapolis, IN: Indiana University Press, 1999.

This edited work addresses a wide range of issues involved in the "rational choice" versus area studies debate that is so well elucidated by David Ludden in the opening article of our special issue. Looking at the "area studies controversy" from the perspective of political scientists, the editors' Introduction underscores questions that we international educators need to address ourselves. It is valuable to wonder about the "uses and abuses" of area studies in planning our overseas programs, or discussing the "internationalization" of our curricula. It is also critical to understand the Eurocentric and overly-simplistic approaches of the social science "rational choice" models. While agreeing that both area studies and the social science theories and methodologies are necessary for a global understanding, the present work places such questions within the context of the Middle East as a stimulus and a model for increasing the value of research about any country or region. 